\title{
QUALIDADE DE VIDA NO TRABALHO: preocupação também para servidores públicos?
}

\section{1- Tania Gonçalves Ferreira Nobre Amorim*}

Doutora em Administração em Estratégias Empresariais pela Universidade Federal da Paraíba - UFPB, João Pessoa/PR, Brasil.

Professora da Universidade Federal Rural de Pernambuco - UFRPE, Recife/PE, Brasil.

tanobre@gmail.com

http://lattes.cnpq.br/2951129655100886 


\section{QUALIDADE DE VIDA NO TRABALHO: PREOCUPAÇÃO TAMBÉM PARA SERVIDORES PÚBLICOS?}

\section{RESUMO}

O tema Qualidade de Vida no Trabalho - QVT vem chamando a atenção de estudiosos, na ultima década, por interferir no desempenho organizacional e tem mostrado que pode elevar o nível de satisfação dos empregados com reflexos sobre o trabalho de cada um e assim melhorar o desempenho de todos. Várias organizações criaram programas de QVT buscando ajudar seus funcionários a manterem um bom nível de qualidade de vida no trabalho, e fora dele, mas a maioria é do setor privado e de grande porte. No setor público, ainda não se evidenciam muitas iniciativas na estruturação e implantação desses programas. 0 presente trabalho é resultado de uma pesquisa que buscou conhecer os pressupostos da qualidade de vida para o servidor público, tomando por base o Ministério Público do Estado de Pernambuco - MPPE. Objetivou avaliar o nível de qualidade de vida percebido pelos servidores, no exercício das atividades profissionais, em relação aos principais aspectos que envolvem a QVT. Os servidores do MPPE demonstraram uma percepção positiva quanto ao nível QVT existente na organização, nos principais aspectos relativos ao trabalho: condições e instrumentos de trabalho, jornada de trabalho, remuneração e natureza do trabalho realizado. Ressalta-se que ainda não existe um programa estruturado de QVT no MPPE.

\section{Palavras-chave}

Qualidade de vida no trabalho; organizações públicas.

\section{QUALITY OF WORKING LIFE: PUBLIC EMPLOYEES PREOCCUPATIONS?}

\section{ABSTRACT}

During the past decade researchers have shown increased interest in the relationship between organization work and quality of work life - QWL. The improvement in QWL is interesting because it can lead to higher work satisfaction rates, and better morale for all employees. Several organizations have QWL Programs to help managers in determining what they can do to improve general quality of working life among staff. Most public organizations do not have QWL programs. This paper presents the results of a research conducted in a public organization: Ministério Público do Estado do Pernambuco - MPPE. The major objective of the present study was measure the level QWL and employee's feelings about it. It was detected a positive level in main aspects of work: working conditions, work instruments, General well-being assesses, working hours, payment, pressures and stress at work. It's important to highlight that there wasn't a structured a QWL Program at the MPPE.

\section{Keywords}

Quality of working life; public organizations. 


\section{Introdução}

A preocupação com a Qualidade de Vida no Trabalho não é algo recente. Entretanto, a implementação de programas específicos ocorreu mais recentemente, devido, principalmente, à percepção de que aspectos relativos à saúde física e mental no ambiente de trabalho têm impacto direto sobre o nível de produtividade dos funcionários e influenciam nos resultados organizacionais. Assim, segundo Edwards et al (2009) elevar o nível de qualidade de vida dos trabalhadores é interessante porque pode mostrar que a satisfação no trabalho pode ser elevada explorando novos e melhores meios de realização das tarefas.

Inicialmente, os estudos sobre a QVT focalizavam aspectos individuais restritos e relativos ao bem-estar do trabalhador no ambiente de trabalho. Posteriormente, procurou-se solucionar problemas relativos ao enriquecimento da tarefa, objetivando estimular a criatividade no exercício funcional, ampliar a participação nas decisões e reduzir a impessoalidade nas relações de trabalho. Hoje, o tema constitui item obrigatório no planejamento estratégico corporativo e é tratado como uma vantagem competitiva no mercado, necessário para atrair e manter bons profissionais.

No final da década de 1970, Westley e Walton apresentavam abordagens semelhantes às concepções atuais sobre QVT. Situavam como pontos centrais aspectos relacionados à equidade salarial, segurança no emprego, motivação, realização e participação nas decisões do próprio trabalho. Para Westley (1979) problemas políticos levam a insegurança no emprego, problemas econômicos levam a injustiças, problemas psicológicos muitas vezes levam a alienação; e os sociológicos à falta de envolvimento no trabalho. Hoje, a concepção sobre QVT tende a ser consensual acerca da multidimensionalidade do fenômeno.

A Gestão de Pessoas incorporou a preocupação com a QVT, indo além dos aspectos físicos e ambientais do trabalho, mas também a saúde e o bem-estar do trabalhador, dentro e fora do local de trabalho, procurando estabelecer um equilíbrio entre dois interesses frequentemente antagônicos: de um lado, o ambiente de trabalho e de outro, o interesse da organização em obter melhores níveis de qualidade e produtividade, a fim de ampliar a participação no mercado e elevar a lucratividade (AMORIM, 2003). Nascimento-Silva et al (2007) afirmam que a qualidade de vida no trabalho tem desafiado estudiosos, cientistas e gerentes, na busca por encontrar um modelo explicativo capaz de gerenciar este fenômeno que, muitas vezes, pode comprometer o futuro de uma organização.

Essa preocupação com a qualidade de vida tem motivado programas específicos de combate às doenças ocupacionais e, sobretudo, mecanismos de defesa do bem-estar do trabalhador, integrando políticas de recursos humanos. São os programas de QVT, que visam facilitar e satisfazer às necessidades do trabalhador no desenvolvimento de suas atividades na organização, tendo como premissa "o fato de que as pessoas são mais produtivas quanto mais estiverem satisfeitas e envolvidas com o próprio trabalho" (CONTE, 2003, p.33).

Na visão de França e Rodrigues (2002) os programas de QVT proporcionam redução substancial nos índices de rotatividade e absenteísmo, relativos a problemas de saúde; baixa motivação; insatisfação salarial; conflitos internos; stress; mau atendimento a clientes internos e externos; sabotagem; militância sindical e consequentes ações na Justiça do Trabalho. Os programas também buscam, sempre que possível, atender aos anseios individuais de cada empregado, uma vez que a realidade do quadro de recursos humanos não é mais aquela composta apenas por indivíduos de comportamento padronizado, mas caracterizada pela diversidade humana no ambiente de trabalho.

Dessa forma, o bom nível de atendimento às necessidades dos clientes depende, em grande parte, da satisfação do funcionário, público ou privado, durante a consecução do seu exercício funcional. Para melhorar o nível de atendimento ao contribuinte-cliente, cada órgão e entidade pública deve implementar programas de QVT, objetivando garantir o bem-estar dos servidores no ambiente de trabalho.

Kanaane (citado por Faller, 2004) considera que a QVT engloba dimensões individuais e situacionais. A dimensão individual abrange as necessidades humanas e o impulso, enquanto força que move as pessoas emocionalmente em suas decisões. E a dimensão situacional composta pelos tipos de tecnologia, políticas organizacionais, cultura da organização, etc. Vaananen et al. (2003) constataram em seus estudos que os dias de absenteísmo aumentam quando os problemas mentais como o estresse se somam a problemas físicos (DORT), resultantes de posturas e processos inadequados de trabalho. Daí a importância da preocupação com ações que proporcionem uma melhor condição de trabalho e QVT. 
Dessler (1999) defende que empregados comprometidos tendem a ter melhores registros de atendimentos e maior domínio do trabalho, prevalecendo um melhor desempenho. Para Meyer e Allen (1997) os funcionários são mais propensos a desenvolver o comprometimento afetivo quando são tratados de maneira justa pela organização, suas contribuições são valorizadas e têm o senso de sucesso no seu trabalho. O comprometimento seria então influenciado pela qualidade de vida percebida pelos funcionários. Assim, entende-se que aliar ações que proporcionem o bem-estar dos funcionários a outras práticas de gestão de pessoas pode contribuir com o nível de satisfação e comprometimento organizacional.

Estudos desenvolvidos no Brasil sobre QVT são inúmeros. Silva (2001) identificou que as ações relacionadas à QVT e praticadas pela empresa foram consideradas muito importantes pelos funcionários e que, mudanças no salário e na segurança do emprego exercem forte impacto na QVT. Medeiros (2002) detectou que a falta de participação, autonomia e perspectiva de crescimento profissional, bem como o tratamento imparcial e falta de segurança no emprego, são variáveis que reduzem a QVT. Já Rocha \& Felli (2004) e Lacaz (2000) acreditam na necessidade que as pessoas têm de participarem da solução de problemas e tomada de decisões, e isso eleva a percepção do nível de QVT. Já os estudos de Tolfo e Piccinini (2001) levaram a acreditar que, as empresas consideradas os melhores lugares para se trabalhar, oferecem vantagens aos seus empregados tais como: descentralização da gestão, premiação pelos resultados, comunicação aberta, ambiente agradável para trabalhar, programas de QVT e possibilidade do funcionário se tornar sócio ou dono da empresa. Romanzini (2002), por sua vez, buscou identificar como os integrantes de dois provedores de acesso à internet percebem a QVT em seu ambiente profissional, e descobriu que problemas no relacionamento interpessoal, longas jornadas de trabalho e problemas nas relações com a família e o trabalho, estavam reduzindo a qualidade de vida desses trabalhadores.

Todos esses estudos confirmam pressupostos estabelecidos nos modelos de Westley e Walton que, já na década de 70, defendiam a gestão das pessoas no ambiente de trabalho, como propulsor do desempenho e clima organizacional, além de inserirem aspectos específicos á realidade organizacional estudada pelos autores.

A aplicação da QVT na administração pública é capaz de preencher uma lacuna verificada, ao longo dos anos, no nível de tratamento oferecido ao servidor público relativa à valorização do seu trabalho e preocupação com o seu bem-estar e o de sua família. O gestor público tem maior dificuldade em desenvolver seu processo de gestão e decisão, pois se encontra constantemente preso às amarras legais, como limites de investimentos estabelecidos no orçamento, licitação, estrutura de cargos e carreira dos servidores, dentre outros.

McDaid, Curran e Knapp (2005) defendem que o impacto social e econômico é substancial, mas há pouca iniciativa governamental na melhoria das condições do trabalhador e este é o principal desafio para o século atual, ou seja, haver um crescimento econômico e desenvolvimento das nações, mas que também haja a promoção de elevados níveis de saúde pública, desenvolvimento sustentável do bem-estar social e inclusão social.

Sá et al (2007) defendem que a QVT é um tema ainda pouco explorado na prática gerencial das organizações do setor público. Embora a temática tenha recebido bastante atenção nos últimos anos, ainda existe alguma incerteza com relação ao âmbito e responsabilidades por sua gestão.

O presente trabalho é resultado de uma pesquisa que buscou conhecer os pressupostos da qualidade de vida para o servidor público, tomando por base o Ministério Público do Estado de Pernambuco - MPPE. Objetivou avaliar o nível de qualidade de vida percebido pelos seus servidores em relação aos principais aspectos que envolvem o tema: condições de trabalho, instrumentos de trabalho, jornada de trabalho, remuneração e natureza do trabalho

\section{A importância da Preocupação com a Qualidade de Vida no Trabalho nas Organizações}

Os principais modelos de QVT na visão de Fernandes (1996) são os de: Nadler \& Lawler (1983), Hackman \& Oldhan (1975) e Walton (1975). Estes modelos valorizam a natureza do trabalho e afirmam que as dimensões do cargo são determinantes da QVT, pelo fato de oferecerem recompensas intrínsecas que produzem a satisfação no cargo, motivando as pessoas para o trabalho. Assim, os estudos de QVT normalmente abrangem as grandes dimensões do trabalho humano: as condições físicas e ambientais, as condições organizacionais, envolvendo clima, gestão e ações praticadas por toda a administração. 
O atual entendimento sobre Qualidade de Vida no Trabalho é que ela envolve não só os aspectos físicos e ambientais, mas também o bem-estar do empregado dentro e fora do local de trabalho (ROSSI, 2002). O exercício profissional tem ocupado a maior parte do tempo diário na vida das pessoas e, influencia na dinâmica das relações sociais, sobretudo no âmbito familiar. Na visão de vários autores, dentre eles Marques et al (2003) e Moraes (2000), o campo de pesquisa para QVT reúne aspectos relacionados à motivação, fatores ambientais, ergonômicos e de satisfação no trabalho, enfim, busca a completa situação do homem e da sua relação com o trabalho. Bastos, Souza e Costa (2006) salientam que a preocupação com QVT tem aumentado, influenciada pela difusão de novas tecnologias de gestão organizacional. O bem-estar do trabalhador torna-se uma das condições básicas para que o indivíduo desenvolva todo o seu potencial. Sparks e Cooper (1999) defendem a importância de se avaliar separadamente aspectos da saúde ocupacional, física e mental dos trabalhadores e das características organizacionais.

A QVT também pode ser vista como parte integrante de programas de Responsabilidade Social em muitas organizações (SILVA, 2001). Nesses programas a empresa busca garantir o bem-estar do empregado no ambiente de trabalho, focalizando as condições do ambiente interno e externo, natureza do cargo ocupado, benefícios e remuneração justa.

As Condições do ambiente de trabalho, como já foi citado, estão entre as grandes preocupações quando se pretende trabalhar um programa de QVT, também na visão de Tachizawa, Ferreira \& Fortuna (2004). Limongi-França (2004) aponta as questões comportamentais relativas às necessidades humanas e aos comportamentos desenvolvidos no ambiente de trabalho como fatores tão relevantes quanto às questões de identidade e variedade da tarefa, que também são mencionadas em estudos internacionais por autores como Cahill e Schnall (1999) e Quinlan, Mayhew e Bohle (2001). Estes autores detectaram que a tendência de reestruturação do emprego tem causado significativos reflexos sobre os trabalhadores, gerando mais estresse e doenças tanto físicas como psicossomáticas. Destacam o aumento da jornada de trabalho, preocupações oriundas de funções gerenciais e a sobrecarga de responsabilidades como alguns dos principais aspectos que devem ser contemplados nos programas de QVT das organizações em que realizaram suas pesquisas, idéias também aplicáveis à realidade organizacional brasileira.

Assim, o excesso de atenção ao trabalho pode levar a tensões em outros patamares da vida do trabalhador gerando insatisfação em alguma dimensão da vida pessoal. A busca por recompensas no trabalho leva ao aumento do tempo dedicado ao trabalho, que pode ocasionar um aumento na performance profissional tornando esta dimensão mais valorizada, e este desequilíbrio entre o pessoal e o profissional segundo os estudos de Edwards e Rothbard (2000) estão mais presentes nos executivos. Um dos efeitos não só para o trabalhador, mas também para o executivo atual, segundo Huy e Mintzberg (2003) é o aumento das tarefas e responsabilidades, além do alto ritmo que têm de ser realizadas, aumentando também a sensação de estar sempre devendo alguma tarefa e se tornado mais uma fonte de tensão para o desempenho do trabalhador. Resultados semelhantes foram identificados no Brasil nos estudos de Mendes e Cruz (2004) e Limongi-França (2007).

Em outro sentido, Mendes e Cruz (2004) afirmam que as doenças mentais ocupacionais são resultantes de um conjunto de indicadores negativos de saúde, tais como: sofrimento e estresse e não apenas como sintomas isolados. Assim, recomendam favorecer um ambiente de trabalho onde exista prazer, satisfação e bem-estar. Estudos internacionais também têm se preocupado com essa temática, quando identificam causas e fontes de estresse influenciadoras do desempenho dos funcionários. Dentre eles destacamos os estudos de Levi (1981) em que concluíram sobre a forte influência do estresse nas ausências por motivo de saúde com duração igual ou inferior a 15 dias. Já na pesquisa de Roxburgh (2004) foi detectado que os solteiros contraem maior número de doenças físicas e mentais que os funcionários casados, apesar de não termos encontrado dados nacionais que corroborem com estes resultados.

Segundo Roscigno e Rodson (2004) o absenteísmo, ou seja, um atraso na chegada ou uma saída mais cedo do local de trabalho, também poderiam representar resistência, gerar impactos no desempenho organizacional e serem resultados da qualidade de vida dos trabalhadores. Já os estudos de Muchinsky (2003) mostraram que as ausências temporárias estão correlacionadas com a satisfação profissional em $25 \%$ dos pesquisados. 0 autor conclui que em doenças simples ou moderadas, os trabalhadores satisfeitos estão mais dispostos a não faltarem ao trabalho.

Filho (2001) se preocupou com os aspectos físicos do trabalho e sua influência direta no nível de QVT. O controle do ruído que pode causar alterações gastrointestinais, na visão, cardiocirculatórias, ansiedade, irritação, redução do rendimento, aumento do número de erros e possibilidade de acidentes. A temperatura 
e o conforto térmico do ambiente de trabalho, com o controle da umidade e da ventilação, também influenciam na QVT do trabalhador.

A qualidade e a disponibilidade de instrumentos de trabalho são itens fundamentais para a competitividade da organização, na visão de Bohlander (2003), bem como, a ergonomia dos móveis em relação à saúde e satisfação do empregado. Milkovich \& Boudreau (2000) acreditam que a jornada de trabalho gera conflitos e estresse, pelo tempo dedicado à organização e falta de tempo para os familiares e lazer. Lembram que é importante existir o alinhamento interno e externo da remuneração, pois ela tem impacto direto na vida social do indivíduo, por possibilitar conforto a família, assistência à saúde, educação, lazer e, principalmente, status social. Portanto, também é foco de constantes insatisfações no ambiente de trabalho.

Como exposto, a forma como o trabalho é realizado, é determinada não só pelas características individuais do ocupante do cargo, mas também pela estrutura organizacional, tecnologia existente no mercado e no ambiente social das organizações. Desta forma, tudo que envolve o ambiente de trabalho deve ser preocupação dos estudos de QVT, em especial as condições físicas, as tarefas, os planos de cargos e salários, as pessoas e os gestores. As decisões gerenciais devem ser preocupação da cúpula organizacional, a fim de que associem práticas gerenciais que favoreçam o melhor ambiente de trabalho. No seu sentido mais amplo este ambiente favorecerá aos funcionários desenvolverem suas atividades de forma plena, tranqüila, segura e assim reconheçam e percebam que são valorizados e se comprometam efetivamente com os resultados.

\section{Método}

\subsection{A Organização Estudada}

O Ministério Público do Estado de Pernambuco - MPPE é um órgão essencial à função jurisdicional do Estado. Possui atribuições específicas, dentre elas a promoção privativa da ação penal pública, observância do efetivo respeito pelos Poderes Públicos e dos serviços de relevância pública aos direitos assegurados na constituição. Os serviços são desempenhados por servidores do Quadro de Pessoal de Apoio TécnicoAdministrativo, em nível operacional (auxiliar e técnico ministerial) e nível superior.

No Estado de Pernambuco, a sede da Procuradoria Geral de Justiça, órgão responsável pela administração superior da instituição, cujo titular é o Procurador-Geral de Justiça e está localizada no Recife. O Procurador-Geral de Justiça é escolhido pelo Governador do Estado dentre os membros de uma lista tríplice elaborada dentre integrantes da carreira, para um mandato de dois anos, prorrogáveis uma vez por igual período. O ingresso na carreira de promotor de justiça dar-se mediante concurso público de provas e títulos e observada, nas nomeações, a ordem de classificação.

As atividades-fim do MPPE foram divididas em áreas de concentração destinadas a atender com maior celeridade as mais diversas demandas sociais, tais como: defesa do patrimônio público, infância e adolescência, idosos, meio ambiente, consumidor, direitos humanos, educação, reforma agrária, criminal, falência e concordata, saúde e terceiro setor (fundações privadas e entidades da sociedade civil). Para cada área há uma promotoria de justiça responsável pela observância dos direitos coletivos da sociedade em cada comarca do Estado.

Os serviços destinados a atividade-meio são desempenhados por servidores do Quadro de Pessoal de Apoio Técnico-Administrativo, através de concurso público, compreendendo três modalidades de cargos para provimento efetivo na carreira: auxiliar ministerial (nível fundamental), técnico ministerial (nível médio) e analista ministerial (nível superior). As atividades de nível operacional (auxiliar e técnico ministerial) englobam atividades de complexidade variada, podendo exigir conhecimento e domínio de conceitos mais amplos ou campos de conhecimentos específicos (cursos técnicos), exigindo-se escolaridade formal compatível (1ㅇou 2 o graus). As atividades de nível superior, por outro lado, exigem graduação de nível superior ou habilitação legal equivalente.

A direção superior dos serviços de apoio técnico-administrativo é delegada ao Secretário-Geral do Ministério Público por ato administrativo do Procurador Geral de Justiça, distribuída através dos seguintes órgãos ministeriais: Diretoria de Informática; Diretoria de Administração; Diretoria de Finanças e Diretoria de Recursos Humanos. Integra ainda a estrutura-meio ministerial e sob o comando da Secretaria-Geral os 
seguintes órgãos de apoio: Assessoria de Imprensa; Assessoria de Planejamento; Assessoria Jurídica; Auditoria Interna; Centro de Apoio Técnico - CAT; Biblioteca e Comissão Permanente de Licitação.

Os servidores à disposição representam a maioria da força de trabalho do MPPE. Segundo dados de 2005, os servidores à disposição totalizaram 275 (duzentos e setenta e cinco) pessoas, enquanto os servidores integrantes da instituição (quadro efetivo e suplementar) 167 (cento e sessenta e sete) indivíduos. Um total de 442 (quatrocentos e quarenta e dois) servidores. Dado que não foi significativamente alterado até 2008.

O atual Regime Jurídico dos servidores do MPPE está disposto na Lei Estadual no 12.342, de 28 de janeiro de 2003. Os servidores recebem, além do vencimento mensal, auxílio alimentação. A carga horária semanal totaliza 30 horas, cumpridas de segunda-feira a sexta-feira, das $12 \mathrm{~h}$ às $18 \mathrm{~h}$, sem prejuízo dos plantões aos sábados, domingos e feriados, devidamente remunerados com os acréscimos permitidos em lei. A estrutura da remuneração do quadro efetivo e suplementar dos servidores é hierarquizada em grupos ocupacionais, escalonados em referências. O desenvolvimento na carreira ocorre mediante processos de promoção e progressão, sempre precedidos de avaliação de desempenho efetuada por Comissão, cumprindo o interstício legal de 1 ano.

O MPPE serviu de base para a coleta de dados da pesquisa realizada para elaboração deste trabalho, quando foi identificado que não havia um programa estruturado de QVT, ou mesmo, informações estruturadas relativas aos aspectos físicos, psicológicos e motivacionais dos servidores.

\subsection{Caracterização da Pesquisa}

A metodologia de pesquisa baseou-se no modelo de taxionomia proposto por Vergara (1997), segundo o qual estabelece o tipo de pesquisa quanto aos fins e quanto aos meios. Quanto aos fins, a pesquisa é descritiva, porque pretende expor as características da política de RH do MPPE, além de descrever opiniões e expectativas dos servidores. É também explicativa porque procurou analisar as informações disponíveis, procurando avaliar a necessidade de implantação de um programa de QVT na instituição. A pesquisa descritiva justifica-se, pois segundo Gil (1994 p. 45) pode levantar opiniões, atitudes e crenças, objetivando a "descrição das características de determinada população, fenômeno ou o estabelecimento de relações entre variáveis". Quanto aos meios, a pesquisa é bibliográfica e de campo. É bibliográfica porque todo o arcabouço teórico foi extraído de fontes bibliográficas relacionadas à literatura disponível da área. É de campo porque os dados analisados foram coletados a partir da aplicação de questionários em duas unidades a Diretoria de Recursos Humanos e a Diretoria de Informática.

\subsection{Descrição da Amostra}

A amostra foi construída por adesão voluntária dos servidores das duas diretorias e totalizou 45 servidores que representa $10,2 \%$ do total de servidores em todo o estado (442 indivíduos), sendo 25 servidores do quadro efetivo e suplementar e 20 à disposição da instituição. A amostra coletada foi composta majoritariamente por servidores do quadro efetivo (55,5\%), o que torna relevante a avaliação do nível de QVT, uma vez que estes profissionais permanecerão, de uma maneira geral, por mais tempo do que aqueles à disposição, cujo contrato de cessão junto ao órgão de origem tem periodicidade anual.

\subsection{Caracterização do Instrumento de Coleta de Dados}

O instrumento de coleta de dados utilizado foi construído a partir do levantamento bibliográfico realizado seguindo os preceitos dos autores estudados. Dentre eles destacados os mais tradicionais tais como Walton (1975), Hackman \& Oldhan (1975), Westley (1979), Nadler \& Lawler (1983) e Levi (1981), e também autores mais atuais como Fernandes (1996), Rossi (2002) e Limongi-França (2004). O instrumento foi dividido em 6 (seis) áreas temáticas:

- Dados Gerais: buscou identificar as características básicas da amostra de servidores: efetivo ou disposição, sexo, escolaridade e faixa etária.

- Condições do Ambiente de Trabalho: buscou identificar as condições do percebidas pelo servidor em relação aos seguintes aspectos: iluminação, temperatura, qualidade do ar, tamanho do ambiente, 
limpeza, manutenção do imóvel e água potável, a partir de uma escala Likert de cinco pontos (muito ruim, ruim, regular, bom e muito bom).

- Instrumentos de Trabalho: buscou identificar a qualidade e disponibilidade das ferramentas e equipamentos utilizados no exercício funcional como: qualidade e disponibilidade de computadores, manutenção dos computadores e móveis e utensílios, qualidade e disponibilidade dos materiais de expediente e ergonomia.

- Jornada de Trabalho: buscou verificar o nível de satisfação relativo ao horário de trabalho, acessibilidade do local de trabalho, permanência após o horário de expediente e transporte coletivo.

- Remuneração: buscou verificar o nível de satisfação, expectativas de poder aquisitivo na aposentadoria, dependentes, recebimento de outras fontes, nível de satisfação em relação ao plano de cargos e carreiras e equidade interna e externa da remuneração.

- Natureza do Trabalho: buscou avaliar a natureza das tarefas desempenhadas pelo servidor, em relação à variedade, autonomia, oportunidade de desenvolvimento, significado e integração, além do nível de percepção quanto ao desenvolvimento de competências e relevância social do trabalho.

Alguns detalhes importantes não foram incluídos no questionário a fim de facilitar a adesão voluntária ao preenchimento. Um deles se refere à identificação da unidade lotação, o que permitiria avaliar, de forma mais específica, as condições do ambiente de trabalho. Outro dado omitido foi a identificação do cargo ocupado (auxiliar ministerial, técnico ministerial ou analista ministerial) também porque seriam facilmente identificados os respondentes, já que alguns cargos são ocupados por poucos servidores, como os analistas ministeriais, podendo prejudicar o caráter anônimo da amostra e/ou suas respostas.

\subsection{Caracterizações dos procedimentos de análise dos dados}

Foram realizadas diversas visitas ao MPPE, em que foram explicados os objetivos da pesquisa e os procedimentos a serem adotados junto aos servidores, tendo-se obtido aprovação pelas duas diretorias e o apoio de um servidor na coleta dos dados. Os questionários foram reproduzidos individualmente e entregues pessoalmente a cada um dos funcionários que aceitaram participar, orientando-os quanto à forma de resposta e explicando os objetivos da pesquisa.

Os dados foram analisados inicialmente utilizando-se basicamente estatística descritiva e análise de conteúdo das perguntas abertas, que eram justificativas de quatro (04) das perguntas fechadas. Para testar a significância estatística das diferenças encontradas entre os valores das diversas variáveis associadas à Qualidade de Vida no Trabalho em relação aos aspectos pessoais (sexo, idade e escolaridade), bem como às circunstâncias metodológicas acerca do objetivo desta pesquisa, foi considerada uma abordagem não-paramétrica.

Sobre esses testes não-parametricos, Bisquerra, Sarriera e Martinez (2004) ressaltam que eles são úteis quando não há a necessidade de fazer suposições sobre as distribuições ou origem das variáveis que estão sendo estudadas. De acordo com Levin (1987), estes testes não exigem os pressupostos inerentes à normalidade de distribuição ou nível intervalar de mensuração para as variáveis investigadas. Assim, nesta pesquisa foram utilizados dois testes não-paramétricos: o teste de Mann-Whitney $U$ e o teste de KruskalWallis.

O teste não-paramétrico de Mann-Whitney $U$ é utilizado para avaliar se duas amostras podem ser consideradas como sendo provenientes da mesma população, ressaltando ainda que, na medida em que o tamanho das amostras se aproxima de 30, a distribuição de U tende rapidamente à normalidade. Já Stevenson (1986) considera que o teste não-paramétrico de Mann-Whitney U pode ser utilizado para testar se duas amostras provêm de populações que possuem médias iguais. E de acordo com Levine, Berenson e Stephan (2000), o teste de Kruskal-Wallis investiga a significância das diferenças observadas em três (ou mais) grupos de dados. Para ele, este teste possui o mesmo nível de eficácia do teste F, bem como a estatística de seu teste de hipótese se aproxima de uma distribuição qui-quadrada, na medida em que cada um dos grupos considerados possua tamanho maior que cinco.

Os procedimentos estatísticos relativos aos testes foram realizados através do auxílio do aplicativo estatístico Statistics for Windows. 


\section{Resultados}

Nesta seção serão detalhados os achados empíricos da pesquisa realizada junto ao MPPE que são fruto dos questionários utilizados junto aos servidores.

\subsection{Dados Gerais}

A faixa etária da maioria $(68,8 \%)$ concentrou-se no intervalo de 31 a 50 anos, considerada um pouco elevada, talvez resultado da ausência de concurso público há cerca de uma década. $57,5 \%$ dos servidores possuem nível superior completo, apesar da maior parte dos cargos exigirem apenas o 2 grau completo. $\mathrm{E}$ $58 \%$ eram homens.

Foram realizados testes para verificar a significância estatística das diferenças entre as diversas variáveis relacionadas à QVT, considerando as variáveis pessoais de sexo, idade e escolaridade. Apenas duas variáveis se mostraram significativamente relacionadas à escolaridade:

a) Necessidade de desempenhar outra atividade, que obteve $p=0,00$, significando que a escolaridade está fortemente relacionada à variável e mostraram que, quanto maior a escolaridade, menor a necessidade de exercer outra atividade fora do MPPE;

b) Autonomia obteve $p=0,01$, significando que a escolaridade está relacionada a ela e que a chance desta conclusão estar errada é de uma em cem. Os resultados mostraram que quanto maior a escolaridade, maior a exigência por autonomia pelo servidor do MPPE.

\subsection{Condições do Ambiente de Trabalho}

Uma ampla maioria dos servidores considerou muito bons os seguintes aspectos: iluminação, temperatura, limpeza das salas e dos banheiros, manutenção do imóvel e qualidade da água para consumo. O nível de satisfação referente à qualidade do artambém foi positivo, embora sendo considerado bom pela maioria. Já em relação ao tamanho do ambiente de trabalho a maioria dos servidores está insatisfeita $(70 \%)$, pois consideram que as salas onde trabalham são reduzidas e isto diminui o conforto durante a jornada de trabalho.

\subsection{Instrumentos de Trabalho}

Buscou-se saber se os computadores eram suficientes para a realização do trabalho na percepção do servidor. Faz-se necessário explicar que a distribuição de computadores entre as unidades do MPPE, em termos de quantidade e qualidade, não ocorre de modo uniforme, mas segundo critérios e prioridades estabelecidos pela administração de cada biênio. Este fato, segundo os pesquisados, gera insatisfação principalmente em áreas não priorizadas pela gestão. Assim, 53,3\% dos pesquisados acham insuficientes os computadores para o bom desempenho do seu trabalho.

A qualidade dos equipamentos de informática foi consultada, por ser outro aspecto importante para o bom desempenho das funções, associado ao fato de que sendo uma organização pública a celeridade dos procedimentos de compra e manutenção nem sempre atendem às demandas dos servidores. Segundo os pesquisados, $40 \%$ consideram regular, $31 \%$ boa e $11 \%$ muito boa.

Em relação à qualidade dos materiais de expediente, 33\% consideram regular, 51\% boa e $9 \%$ muito boa. A disponibilidade dos materiais foi considerada para $31 \%$ dos servidores como regular, $56 \%$ boa e $4 \%$ muito boa.

E, para finalizar a análise dos instrumentos de trabalho, contatou-se que a ergonomia relativa aos móveis disponíveis na instituição atende bem às características físicas da maioria dos servidores, pois $60 \%$ dos servidores consideraram boa e $29 \%$ regular.

\subsection{Jornada de Trabalho}

A jornada semanal é de 30 horas, das $12 \mathrm{~h}$ às $18 \mathrm{~h}$ de segunda-feira a sexta-feira, com plantões esporádicos aos sábados, domingos e feriados, devidamente remunerados com os acréscimos permitidos 
em lei. $89 \%$ dos servidores estão satisfeitos embora $45,2 \%$ se considerem mais produtivos no turno da manhã. A permanência fora dos limites da jornada de trabalho é, muitas vezes necessária, para o cumprimento das atividades segundo $58 \%$ dos pesquisados, devido à carência de servidores. $O$ nível de acessibilidade ao local de trabalho foi considerado bom e muito bom para $64 \%$ dos servidores.

\subsection{Remuneração}

O nível de satisfação em relação à remuneração foi responsável por um dos mais baixos índices de satisfação dos servidores, apresentando o índice de $51 \%$ dos servidores considerando a remuneração como regulare $24 \%$ ruim. O gráfico 1 abaixo, detalha esses dados:

Gráfico 1 - Nível de Satisfação da Remuneração

\section{Nível de Satisfação Atual da Remuneração}

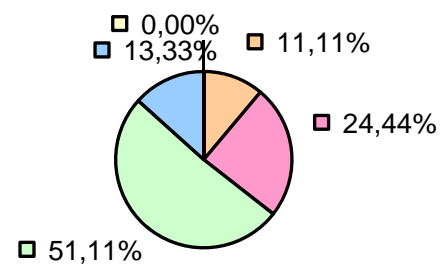

\begin{tabular}{|ll|}
\hline 口Muito Ruim & 口Ruim \\
口Regular & वBom \\
वMuito Bom &
\end{tabular}

O nível de expectativa relativo ao poder aquisitivo do servidor após a aposentadoria também foi avaliado de forma negativa pelos servidores com $20 \%$ considerando muito ruim e $36 \%$ ruim. Nas justificativas a esta questão foi destacada a não incorporação da gratificação de função aos proventos de aposentadoria. A pesquisa identificou também que em torno de $40 \%$ dos servidores desempenham outras atividades profissionais para complementar a sua renda mensal.

Em relação ao aspecto da equidade da remuneração os resultados indicam que para $30 \%$ foi regular, para $22,5 \%$ dos servidores é ruim e para $12,5 \%$ muito ruim. Resultado semelhante, embora um pouco mais negativo, foi obtido nas respostas dos servidores em relação à equidade externa da remuneração recebida, em que $37 \%$ classificaram como regulare cerca de 35\% como ruim e 9,5 muito ruim.

O nível de satisfação em relação ao Plano de Cargos e Salários do MPPE, segundo os servidores efetivos não é bom para a maioria (64\%) que o definiram como muito ruim ou ruim, conforme detalhamento no gráfico 2 a seguir.

Gráfico 2 - Nível de satisfação relativo ao plano de cargos e salários

Nível de Satisfação Relativo ao Plano de Cargos e Salário Atual (apenas servidores do quadro efetivo ou suplementar)
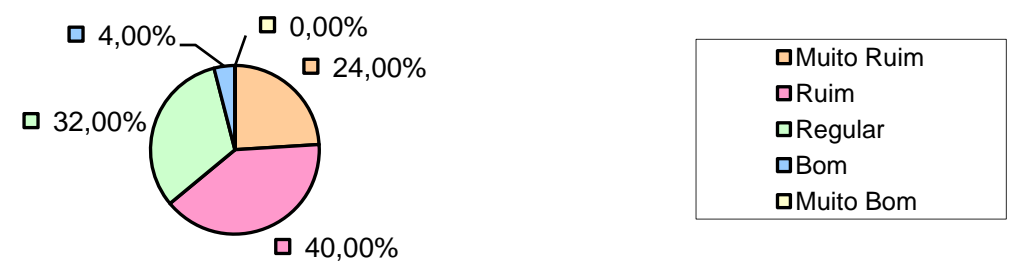

\subsection{Natureza do trabalho}

Em relação a Variedade e Autonomia das tarefas desempenhadas $80 \%$ dos servidores pesquisada consideram muito boa e boa. Consultados sobre a oportunidade de desenvolvimento profissional no MPPE, $20 \%$ consideraram regular e $44 \%$ boa. O Significado das Tarefas que desempenham para 54,5\% dos servidores é bom, $27 \%$ muito bom e $18 \%$ regular. Já em relação ao aspecto Identidade com a Tarefa, $53 \%$ consideram boa, $11 \%$ muito boa e $29 \%$ regular. 
O desenvolvimento de competências foi considerado satisfatório, entretanto para $18,2 \%$ consideram ruim e 4,5\% muito ruim a valorização da instituição pelo auto-desenvolvimento intelectual do servidor. E a relevância social do trabalho percebida é um aspecto importante para o exercício funcional e QVT, 31\% dos servidores consideraram muito boa e $46,7 \%$ boa.

\section{Análise dos Resultados e Considerações Finais}

A importância da atenção com a Qualidade de Vida no Trabalho independente da natureza pública ou privada da organização e não deve ser negligenciada pelos gestores, uma vez que pode comprometer o futuro da organização, como defendem Tolfo e Piccinini (2001), França e Rodrigues (2002), Limongi-França (2004) e Nascimento-Silva et al (2007), dentre outros. O estabelecimento de um bom nível de atendimento às necessidades dos clientes depende, em grande parte, da satisfação do servidor no trabalho. Assim, para melhorar a qualidade na prestação de serviços, a organização deve garantir o bem-estar dos servidores no ambiente de trabalho (CONTE, 2003) que pode ser garantido a partir da atenção aos aspectos que influenciam na qualidade de vida dos trabalhadores.

Uma das principais dificuldades para a realização da pesquisa foi à falta de interesse de alguns servidores em participarem e outros que concordaram, mas não responderam devidamente os questionários, o que ocasionou em sua não utilização por serem sem identificação e assim não permitirem correções posteriores.

Os servidores que participaram da pesquisa em sua maioria estão entre 31 e 65 anos, têm nível superior, ocupam funções de nível médio e estão há mais de 10 anos no MPPE. As condições do ambiente de trabalho foram consideradas boas em aspectos como iluminação e temperatura para uma ampla maioria. Alguns focos de insatisfação indicam ocorrências localizadas, segundo as justificativas, em que práticas controle gerencial mais efetivas poderiam reduzi-los, como, por exemplo, através do processo de troca de equipamentos de ar-condicionado obsoletos ou manutenção mais rápida e eficaz daqueles que apresentam pequenos defeitos.

Em termos dos instrumentos de trabalho, verificou-se que a distribuição de computadores entre os órgãos do MPPE, em termos de quantidade e qualidade, não ocorre de modo uniforme, mas segundo critérios e prioridades estabelecidos pela administração do biênio, gerando alguma insatisfação dos grupos que se consideram preteridos. Os materiais de expediente, em termos de disponibilidade e qualidade, foram considerados "regular" para pouco mais de um terço dos funcionários, embora tenham sido considerados "bom" para mais de $50 \%$ deles. Desta forma, confirmam o que Limongi-França (2004) defende sobre a influência dos instrumentos de trabalho quando positiva na percepção dos funcionários repercute positivamente na produtividade e resultados organizacionais.

Os índices relacionados à natureza do trabalho foram positivos, o que demonstra que a organização se encontra em um nível relativamente próximo ao padrão de grandes empresas da iniciativa privada ou de economia mista. O servidor do MPPE tem uma clara percepção da natureza do seu trabalho, é capaz de identificar as conseqüências resultantes de seu exercício funcional e, sugerir melhorias. Isto é um importante aspecto impulsionador do desempenho individual e coletivo, como sugerem Medeiros (2002) e Rocha e Felli (2004).

As questões quanto à identidade e variedade da tarefa também foram bem avaliadas pelos servidores favorecendo o desempenho organizacional e isto corrobora com os estudos de Cahill e Schnall (1999) e Quinlan, Mayhew e Bohle (2001) quando afirmam que a sobrecarga de responsabilidades, gera o excesso de atenção ao trabalho, elevando o estresse e desequilíbrio entre a vida pessoal e profissional do trabalhador e reduzindo a identidade com a tarefa.

A compreensão do significado da tarefa é condição fundamental para o sucesso na implantação de programas de QVT. As insatisfações em relação aos instrumentos de trabalho foram mencionadas apenas por uma minoria de servidores. Então, a percepção dos servidores em termos do trabalho e responsabilidades desempenhadas no MPPE é positiva, favorecendo o nível de comprometimento com o trabalho, como afirmam Meyer e Allen (1997) e Medeiros (2002).

A jornada de 30 horas semanais foi muito bem avaliada pelos servidores do MPPE, porém mais da metade deles declarou precisar ficar além do exigido para cumprimento das suas atividades, em certos momentos. Estudos de Milkovich e Boudreau (2000) detectaram que uma longa jornada de trabalho pode 
gerar conflitos pelo tempo dedicado ao trabalho, família e lazer, interferindo na QVT. No caso estudado isso não ocorreu, portanto a jornada de trabalho não foi avaliada como um fator limitador da QVT dos servidores do MPPE.

Pouco mais da metade dos servidores $(51 \%)$ consideraram sua remuneração "regular" e $35 \%$ os que declararam "ruim" e "muito ruim". A remuneração tem impacto direto na vida pessoal e social do trabalhador (Nadler \& Lawler, 1983; Walton, 1975; Hackman \& Oldhan, 1975; Westley, 1979), portanto é importante a preocupação com a equidade salarial e segurança no emprego. O servidor público brasileiro normalmente recebe uma remuneração com baixa equidade externa, mas possui benefícios diferenciados como a estabilidade, que gera segurança no emprego. Como o MPPE é uma organização estadual, o nível de remuneração é menor do que nos órgãos federais e de outros estados da federação, mas possui um razoável nível de equidade interna. O aspecto da remuneração normalmente quando consultado tende a apresentar índices reduzidos de satisfação, tanto em estudos realizados no Brasil como internacionais.

Devido a isso, cerca de $40 \%$ dos servidores realizam outras atividades remuneradas externas ao MPPE que podem chegar a comprometer o seu envolvimento e disponibilidade. Mas a jornada de $30 \mathrm{~h}$ favorece a que isso ocorra, sendo uma realidade em várias outras organizações. O nível de satisfação com o Plano de Cargos e Carreiras também não foi bem avaliado na percepção dos servidores, o que pode vir a comprometer tanto os resultados organizacionais como o bem-estar percebido entre os servidores, como afirmado por Silva (2001).

Diante dos resultados acima analisados, o estudo sobre a percepção dos servidores do MPPE quanto aos aspectos que influenciam na sua qualidade de vida no trabalho apresentou condições favoráveis do ambiente de trabalho em relação à maioria das variáveis estudadas, o que representa uma realidade diferenciada da maioria das organizações do setor público. Nos testes não paramétricos apenas a variável escolaridade apresentou influência no nível de autonomia exigido no trabalho e na necessidade de desempenhar atividades externas remuneradas, ou seja, quanto maior a escolaridade maior é a exigência de autonomia e menor a necessidade de desempenhar atividades externas remuneradas. As demais variáveis relativas ao servidor como idade e sexo não apresentaram influência sobre os principais aspectos da qualidade de vida analisados na pesquisa.

Os resultados do estudo realizado podem servir de base para a gestão do MPPE implantar ações específicas em relação aos aspectos que não foram bem avaliados, apesar de que segundo a percepção dos servidores a grande maioria das variáveis avaliadas está sendo bem gerenciada e oferece um bom nível de aceitação. A questão do Plano de Cargos e Carreiras precisaria ser estudada com maior profundidade, a fim de poder contribuir para a melhoria da QVT e do desempenho organizacional.

Sugere-se como agenda para novas pesquisas a análise do tema Qualidade de Vida no Trabalho em outras realidades organizacionais públicas, oferecendo subsídios para um estudo mais aprimorado das principais variáveis que interferem no nível da qualidade de vida dos trabalhadores, pois o trabalho sendo parte importante de nossas vidas, deve ser fonte de realização profissional, mas para que isso seja efetivo, não pode levar o trabalhador a se tornar seu escravo e muito menos a adoecer pelo excesso de responsabilidades, esforço físico e mental.

\section{Referências}

AMORIM, T. N. G. F. (Org.). Vivendo e aprendendo: melhorando seus relacionamentos na vida e no trabalho. Recife: Editora Universitária da UFPE, 2003.

BASTOS, A. V. B.; SOUZA, J. J. de.; COSTA, V. M. F. Programas de qualidade de vida no trabalho em contextos diferenciados de inovação In: ENCONTRO NACIONAL DOS PROGRAMAS DE PÓS-GRADUAÇÃO EM ADMINISTRAÇÃO, 30, 2006, Salvador. Anais... Rio de Janeiro, ANPAD, 2006.

BISQUERRA, R.; SARRIERA, J. C.á; MARTINÉZ, F. Introdução à estatística. Porto Alegre: Artmed, 2004.

BOHLANDER, G. W. Administração de recursos humanos. São Paulo: Pioneira, 2003.

CAHILL, P. L.; SCHNALL, P. J.P. The impact of lean production and related new systems of work organization on worker health. Journal of Occupational Health Psychology, v. 4, p. 108-130, 1999.

CONTE, A. L. Qualidade de vida no trabalho. Revista FAE Business, n. 7, nov., 2003.

DESSLER, G. How to earn your employee's commitment. Academy of Management Executive, v.13, n. 2, p. 58-67, 1999.

FRANÇA, A. C. e RODRIGUES, A. L. Stress e trabalho. São Paulo: Atlas, 2002. 
EDWARDS, J. R.; ROTHBARD, N. Mechanisms linking work and family: clarifying the relationship between work and family constructs. Academy of Management Review, 25, 178-199, 2000.

EDWARDS, J. et al. The work-related quality of life scale for higher education employees. Quality of Working Life Review, v. 15, n. 3, p. 201-129, nov., 2009.

FALLER, B. C. Motivação no serviço público: um estudo de caso na Secretaria de Administração da Prefeitura Municipal de Santa Cruz do Sul. 2004. 106 f. Dissertação (Mestrado em Administração) - Programa de PósGraduação em Administração, Universidade Federal do Rio Grande do Sul, Porto Alegre, 2004.

FERNANDES, E. C. Qualidade de vida no trabalho: como medir para melhorar. Salvador: Casa da Qualidade, 1996.

FILHO, A. N. B. Segurança do trabalho \& gestão ambiental. São Paulo: Atlas, 2001.

GIL, A. C. Como elaborar projetos de pesquisa. São Paulo: Atlas. 1994

HACKMAN, J. R.; OLDHAM, G. R. Development of the job diagnostic survey. Journal of Applied Psychology, v. 60, ก. 2, 1975.

HUY, Q. N; MINTZBERG, H. The rhythm of change. MIT Sloan Management Review, Summer, p. 79-84, 2003. LACAZ, F. A. C. Qualidade de vida no trabalho e saúde/doença. Ciência \& Saúde Coletiva, n. 5, v. 1, p.151$161,2000$.

LEVI, L. Society, stress, and disease. New York: Oxford University Press, 1981.

LEVIN, J. Estatística aplicada a ciências humanas. 2. ed. São Paulo: Harbra, 1987.

LEVINE, D. M; BERENSON, M. L; STEPHAN, D. Estatística: teoria e aplicações. Rio de Janeiro: LTC, 1998.

LIMONGI-FRANÇA, A. C. Qualidade de vida no trabalho - QVT: conceitos e práticas nas empresas da sociedade pós-industrial. São Paulo: Atlas, 2004.

MARQUES, A. L. et al. Qualidade de vida e estresse no trabalho em uma grande corporação de polícia militar. INTERNATIONAL CONFERENCE OF THE IBEROAMERICAN ACADEMY OF MANAGEMENT, 3, 2003, São Paulo. Proceedings... São Paulo, Iberoamerican, 2003.

MCDAID, D.; CURRAN, C.; KNAPP, M. Promoting mental well-being in the workplace: A European policy perspective. International Review of Psychiatry, v.17, n.5, p.365-373, Oct., 2005.

MEDEIROS, E. G. Análise da qualidade de vida no trabalho: um estudo de caso na área da construção civil. 2002. 137 f. Dissertação (Mestrado em Administração) - Programa de Pós-Graduação em Administração, Universidade Federal do Rio Grande do Sul, Porto Alegre, 2002.

MEYER, J. P.; ALLEN, N. Commitment in the workplace: Theory, research and application. Thousand Oaks: Sage, 1997.

MENDES, A. M.; CRUZ, R. M. Trabalho e saúde no contexto organizacional: vicissitudes teóricas. In: TAMAYO, A. (Org.). Cultura e saúde nas organizações. Porto Alegre: Artmed, 2004. p. 39-55.

MILKOVICH, G. T.; BOUDREAU, John W. Administração de recursos humanos. São Paulo: Atlas, 2000.

MORAES, L. F. R. et al. Diagnóstico de qualidade de vida e estresse no trabalho da Polícia Militar do Estado de Minas Gerais. Relatório de Pesquisa CNPq. Belo Horizonte: CEPEAD/FACE/UFMG, 2000.

MUCHINSKY, P. M. Psychology applied to work. Belmont: Wadsworth/Thomson Learning, 2003.

NADLER, D. A.; LAWLER, E. E. Comportamento organizacional. Rio de Janeiro: Campus, 1983.

NASCIMENTO-SILVA, D. et al. Avaliação da qualidade de vida no trabalho em uma IES paraense. In: ENCONTRO ANUAL DA ASSOCIAÇÃO NACIONAL DOS CURSOS DE GRADUAÇÃO EM ADMINISTRAÇÃO, 18, 2007, Cuiabá. Anais... Rio de Janeiro, ANGRAD, 2007.

QUINLAN, M.; MAYHEW, C.; BOHLE, P. The global expansion of precarious employment, work disorganizaion, and consequences for occupational health: A review of recent research. International Journal of Health Services. v. 31, p. 335-413, 2001.

ROCHA, S. de S. L; FELLI, V. E. A. Qualidade de vida no trabalho docente em enfermagem. Revista LatinoAmericana de Enfermagem, v. 12, n. 1, p. 28-35, jan./fev., 2004.

ROMANZINI, C. D. Qualidade de vida no trabalho em duas empresas prestadoras de serviço de acesso à internet na região de Caxias do Sul. 2002. Dissertação. (Mestrado em Administração). Programa de PósGraduação em Administração, Universidade Federal do Rio Grande do Sul, Caxias do Sul, 2002.

ROSCIGNO, V. J.; RODSON, R. The organizational and social foundations of worker resistance. American Sociological Review, v. 69, n. 39, p. 14-39, Feb., 2004 
ROXBURGH, S. There just aren't enough hours in the day': the mental health consequences of time pressure. Journal of health and social behavior, v. 45, p.115-131, 2004.

ROSSI, Ana M. Autocontrole: uma nova maneira de controlar o stress. Rio de Janeiro: Rosa dos Tempos, 2002.

SÁ, M. A. D. et al. Qualidade de vida no trabalho docente - uma questão de prazer! In: ENCONTRO NACIONAL DOS PROGRAMAS DE PÓS-GRADUAÇÃO EM ADMINISTRAÇÃO, 31, 2007, Rio de Janeiro. Anais... Rio de Janeiro, ANPAD, 2007.

SILVA, A. B. O equilíbrio entre o trabalho e vida pessoal: uma missão (im)possível. 2001. Disponível em http://www.administradores.com.br. Acesso em: 25 maio 2005.

SPARKS, K.; COOPER, C. L. Occupational differences in the work-strain relationship: towards the use of situation-specific models. Journal of Occupational and Organizational Psychology, v. 72, p. 219-229, 1999.

STEVENSON, W. J. Estatística aplicada à administração. São Paulo: Harbra, 1986.

TACHIZAWA, T.; FERREIRA, V. C. P.; FORTUNA, A. A. M. Gestão com pessoas: uma abordagem aplicada às estratégias de negócios. Rio de Janeiro: Editora FGV, 2004.

TOLFO, S. da R.; PICCINI, V. C. As melhores empresas para trabalhar no Brasil e a qualidade de vida no trabalho: disjunções entre a teoria e a prática. In: ENCONTRO NACIONAL DOS PROGRAMAS DE PÓSGRADUAÇÃO EM ADMINISTRAÇÃO, 22, 1998, Foz do Iguaçu. Anais... Rio de Janeiro, ANPAD, 1998.

VAANANEN, A. et al. Job characteristics, physical and psychological symptoms of sickness absence among men and women in the private industrial sector. Social Science and Medicine, v. 57, n. 5, p. 807-824, Sept., 2003.

VERGARA, S. C. Projetos e relatórios de pesquisa em administração. São Paulo: Atlas, 1997.

WALTON, R. Criteria for quality life. In: DAVIS, L. A. B. The quality of working life: problems, prospects and state of the art. New York: The Free Press, 1975.

WESTLEY, W. A. Problems and solutions in the quality of working life. Human Relations Review, v. $32, \mathrm{n} .2$, p. 113-123, 1979. 